\title{
A protocol analysis of urban population spatial distribution under rising sea levels: a case example of Tainan City, Taiwan
}

\author{
C.-H. Lu \& Y.-J. Chen \\ Department of Urban Planning, \\ National Cheng Kung University, Taiwan
}

\begin{abstract}
Global warming and climate change has been affecting our living environment, including rising sea levels, thermal expansion, changes of rainfall and ecosystems. Among these, the rising sea level directly results in an encroaching coastline that invades present land use and influences human inhabited areas. Taiwan, as a subtropical island, would be significantly affected. This paper attempts to explore the impacts of land use changes and population re-distribution against a rising sea level, and selects Tainan city, which is an alluvial fan city in the Taiwan area, as a case example to propose a protocol approach to modelling the effects. Firstly, this paper examined the change of coast line and flood areas when the sea level rises. Following the result of land change, we simulated the reallocation of population distribution by adopting the heuristic Hansen model under the assumption of keeping the land use of the non-flooded areas unchanged. Our current results indicate that the land space is reduced by $1.7 \%, 13 \%$, and $59 \%$ when the sea level rises by $1 \mathrm{~m}, 2 \mathrm{~m}$, and $3 \mathrm{~m}$, respectively. This paper also concludes that the population increases the fastest in currently less developed areas, such as the Annan district, which is the most rural area of Tainan city. On the other hand, the highly developed areas, such as the East and Middle districts, which are the most attractive locations and the transportation centre of Tainan city, would remain as the core area with the highest population density under our assumption of sea level change.

Keywords: global warming, sea level, land use, Hansen model, Tainan City.
\end{abstract}




\section{Introduction}

In recent years, much research has been completed on the issues of the phenomenon of global warming and climate change, which are worsening every year. Among them, the IPCC (Climate Change 2007) proposed the most detailed research report, which emphasizes exploring how to combat the phenomenon of global warming and the record of environmental changes. Yet, Taiwan has not been included in these research reports, and hence the impacts of rising sea levels in the Taiwan area remain unknown. For anyone who cares about the Taiwan environment this is an important issue and the answers are needed.

Taiwan, as a subtropical island, would be undoubtedly significantly affected by global warming. The impacts include rising sea levels, thermal expansion, changes of rainfall and ecosystems, etc. Among these, rising sea levels leads to coastline retreat, which reduces the available land. The land subsidence of coastal areas is getting worse year by year, and tsunamis caused by earthquakes mean its impact will be expanded. The effect of rising sea levels in the Taiwan area, as caused by global warming and according to the topographic map, show the sea level will rise six meters, and Taiwan's urban planning area will be $11.4 \%$ below sea level, of which the southern region and the part of the low-lying areas in the city of Taipei will be effected more seriously, and in the city of Tainan, almost all city land will be below sea level.

Rationally, the original land use of flooded regions caused by rising sea levels will be transferred to the adjacent land in order for the region to meet the demands for land. With regard to industrial land use, it will result in local service-based industries having to migrate to other regions or cities, rather than belonging to the local service industry. Therefore, the effects will not only make changes to the structure of urban land use, but will also affect local industrial structures, urban employment populations, urban scale, etc. Discussions in this study would be under the circumstances based on rising sea level increases, local land-use maps, and investigations of the land use of flooded areas. The city of Tainan is selected as the empirical area. According to the original characteristics, distribution of land use and population distribution of the Tainan area, we expand the study area to adjacent areas to the east side of city. Following the concept of industrial analysis, industries in the selected study areas are characterized into two types: local industry and non-local industry. This study assumed that the land-use of local industry migrates only to local or nearby urban areas. On the other hand, non-local industry is assumed to migrate out of the city to other regions. Based on the previous assumptions, this study redistributes the use of land and population allocation. The urban structure changed under the impacts of rising sea levels would then be simulated by examining the changes of urban population growth or decline in regional areas.

\section{Global warming and rising sea levels}

The main reasons for global warming are the constant developments of human economic activities and increased carbon dioxide from burning fossil fuels after 
the industrial revolution, leading to increases of atmospheric concentrations of greenhouse gases, such as CO2, CH4, N2O, HFCs, PFCs, and SF6 [1, 2, 7, 10]. Enhanced greenhouse gases cause global warming, rising sea levels, ecosystem and biodiversity changes, and pose a great threat to the survival of global ecosystems. As another result of global warming, the overall global climate has also produced the phenomenon of abnormal changes; for example, by the 20th century, the average global surface temperatures rose by about 0.6 degrees. In addition, it appears to have reduced the frequency of extremely low temperatures since 1950 [7]. The average height of global sea levels has risen from 0.1 to 0.2 meters and in the 20th century, the frequency of drought and flood is slightly increased. The frequency of heavy rainfall in the middle and high latitude regions of the northern hemisphere increased by 2 to $4 \%$, and continues to increase by 0.5 to $1 \%$ every 10 years; and by 0.2 to $0.3 \%$ in equatorial regions $[3,6,8]$.

Of all the research on global warming and climate change at present, the IPCC (Climate Change, 2007) is the most detailed research report. Many reports place more emphasis on the track record of the environment and explore how to prevent the phenomenon of global warming. However, the reports on exploring climate change caused by human lifestyles and the structural changes of land use are limited. According to the IPCC on the rising sea levels, the current methods of measurement include two types, tide gauges and satellite altimetry, of which the latter is more accurate and advanced. It is also suggested that the main reason for rising sea levels has three aspects, which are affected by global warming, and includes the thermal expansion of sea water temperature, the melting of glacier ice, and tectonic changes, in which the thermal expansion of sea water temperature is the main reason for rising sea levels, as its impact accounts for more than half. Part of the rising sea levels, according to field observation records, indicates that the rising sea level trend was not significant before the $19^{\text {th }}$ century. Yet, it can be found that the sum of sea level rise from the first century to the $19^{\text {th }}$ century is less than the rise in the $20^{\text {th }}$ century. It is also predicted that speed and height would be more significant in the future $[1,7,10]$.

The calamities of flood land and coastal erosion, caused by rising sea levels of island states and low-lying areas, are the most obvious. However, such coastal areas are usually more economically and socially developed countries, and are also the most concentrated areas of population, accounting for more than $60 \%$ of the world's population [9]; therefore, these areas will be the hardest hit areas of rising sea levels. In addition, the results of rising sea levels have strengthened marine motivations, so that coastal erosion, especially in sandy coastal areas, is suffered more. The results of coastal erosion on beaches will lead to a reduction in recreational locations, as well as impact from damaged tidal ecologies from salt water intrusion, which directly affects the terrestrial runoff and groundwater quality. It effects urban water supply, industrial, and agricultural water uses cause threats to existing drainage and irrigation systems, as seawater intrusion inland through the rivers change the salt water estuary. Thus, coastal cities that rely on underground water supplies will be faced with water quality and water scarcity problems in the future. In addition, in earthquake-prone coastal cities, 
the foundations of buildings will also be harmed by the rising underground water, as rising sea levels are the result of climate warming, the rising of temperatures indicate that vapour in the air is increased. This will lead to increased and accelerated precipitation probability and intensity as the evaporation of rain by temperature increases, which promotes the water cycles that easily form devastating storms. Its effects that will be rising sea levels and increased storm tides, and original embankments and moisture works will be weakened, and thus easily expanding the affected areas and disasters will become heavier.

\section{The influence of Taiwan's land use under rising sea levels}

Taiwan is an island that occupies $36,000 \mathrm{~km}^{2}$ and the length of the coastline is about $1,140 \mathrm{~km}$. The development of Taiwanese cities extends from coastal areas to inland, most economy and human activities are also concentrated on the coastal areas; thus, the impact of rising sea levels on Taiwan are relatively serious. The damage of rising sea levels effects natural environments as well as economic aspects, including:

- Increasing the land use and migration costs as coastlines shrink,

- The direct loss to land and capital from rising sea levels,

- Lost opportunities of building and development,

- Flood damage and sea backward,

- Destroying the existing salt pan, marshlands, wetlands, etc.

With the distribution of the height of sea levels, this paper observes the main urban areas of Taiwan (Fig 1). When the sea level rises six meters, it will conceal 517 hectares of urban area land, about $11.48 \%$ of all island areas. Among these, southern Taiwan is the most serious. Because the urban area is always the main human activity area, timely consideration of the distribution and structure of population and industry, and its relevant countermeasures, in the face of addressing rising sea levels, is critical.

In this research, we take Tainan City as an example to simulate the situation of sea level rising. Tainan is an important and large city in southwest Taiwan, it
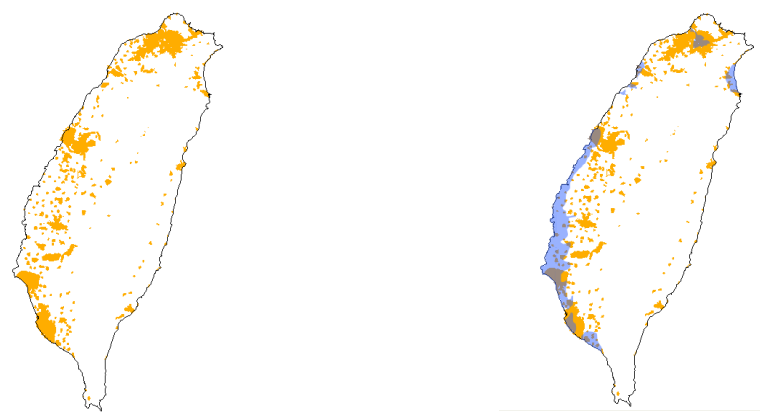

Figure 1: Urban area of Taiwan under a sea level rise of $6 \mathrm{~m}$. 
possess the largest plain and faces the Taiwan-strait, across from China. On a land use map of Tainan, we use contour lines to present the situation of the sea level rising 1,2, and 3 meters (Fig 2).

The results show when the sea level rises one meter, there would be $3,015,248$ square meters of flooding, $1.71 \%$ of land area of the entire city, covering green land, parks, and city vacant lots. When the sea level rises two meters, the flooded lands are 23,020,716 square meters, $13.03 \%$ of land area of the entire city. When the sea level rises three meters, the flooded lands are $103,898,196$ square meters, $58.82 \%$ of land area of the entire city. At this point, industrial areas, residential areas, shopping malls, schools, etc. would be flooded. The extent of the impact, such as population, industry, human lives, and economic systems would be obviously changed, influencing the entire city structure.

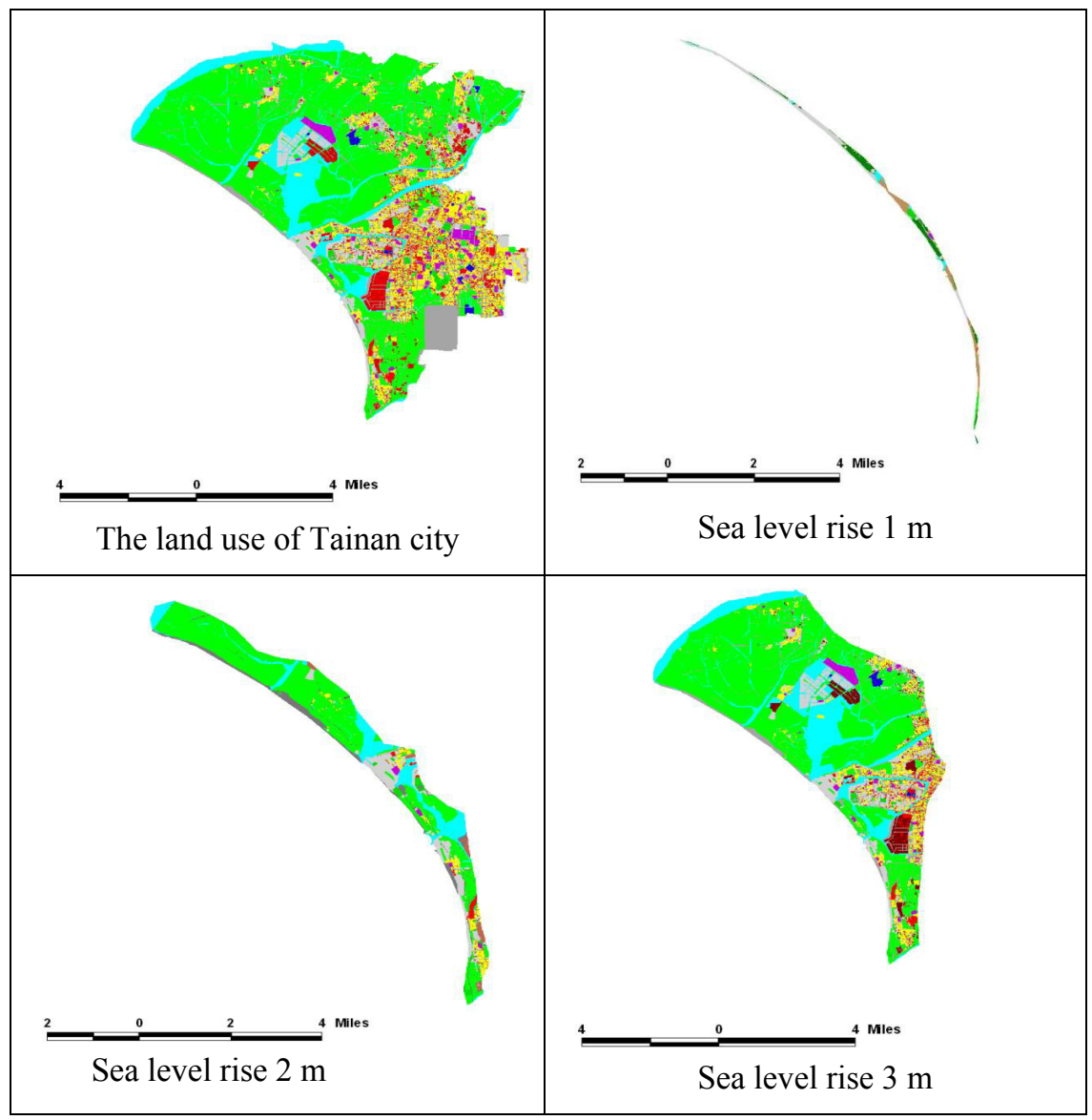

Figure 2: $\quad$ Rising sea level of Tainan City. 


\section{Simulation of population reallocation under rising sea levels}

In this research, we focus on population and industry to discuss migration of the city under rising sea levels. We quote Tainan city as an example and suppose an influencing area, which is the sea level rising three meters, to assign the population. First, we divide the study area into two parts, flooding and nonflooding areas (Fig. 3). The population presently living in flooded areas must move out of the area and can choose to move within the study area or out of the study area. Then through the redistribution of population by Hansen model, we observe the changes of population in our study area. Detailed contents are as follows:

\subsection{Model assumptions}

For simplifying the complicated migration after sea level rising, it was supposed as the following content for this research.

- There are three districts in this area. An area represents the flooding area under the sea level rising, the population will move into areas B or C. People moved to B area will be assigned in this area; and the population moving to $\mathrm{C}$ area are not discussed in this research (Fig. 3).

- This paper supposes that the total population does not change before and after the rising sea level. However, part of the population of the basic industries will move to $\mathrm{C}$ area.

- The administrative area and land use will not change or adjust with passing time.

- To reduce any unstable interference of prediction, it is supposed that the industrial structure and total population are the same before and after the rising sea levels covered in this research.

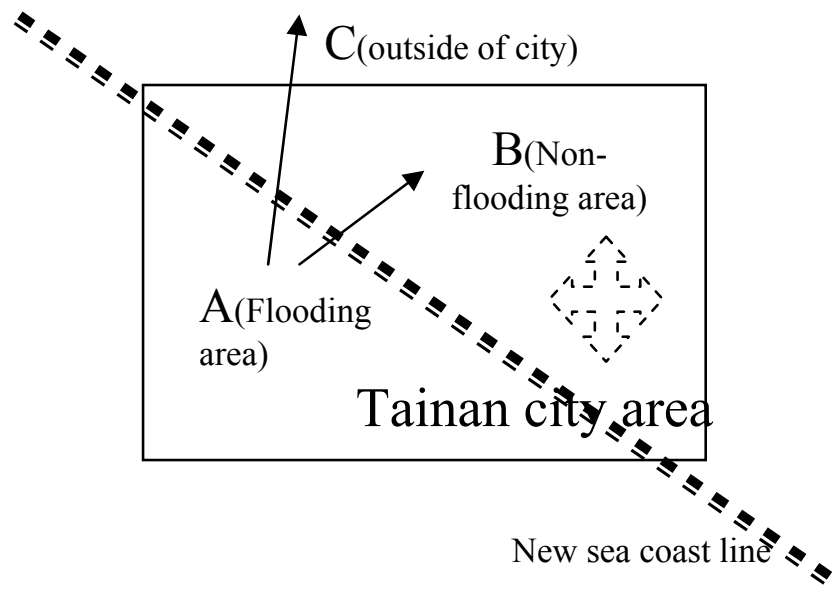

Figure 3: Assumption of model structure. 


\subsection{Study areas}

Because Tainan is close to the sea, and the plain area is an alluvial plain, its sea level is not high; therefore, the impact of rising sea levels here are significant. This research regards Tainan as the survey area, and quotes the basic unit of city administration in collected data. Basic collected data includes population, land quantity, and land use. In addition, this research quotes 13 main communities of living areas from Tainan's comprehensive development plan (Fig 4), and adjusts the boundary to match the rising sea level of 3 meters (Fig 4). Among them, the influence areas include areas $1,3,4,5,6$, and 12, which are flooding areas, while the uninfluenced areas are $2,7,8,9,10,11$, and 13, which are non-flooding areas.
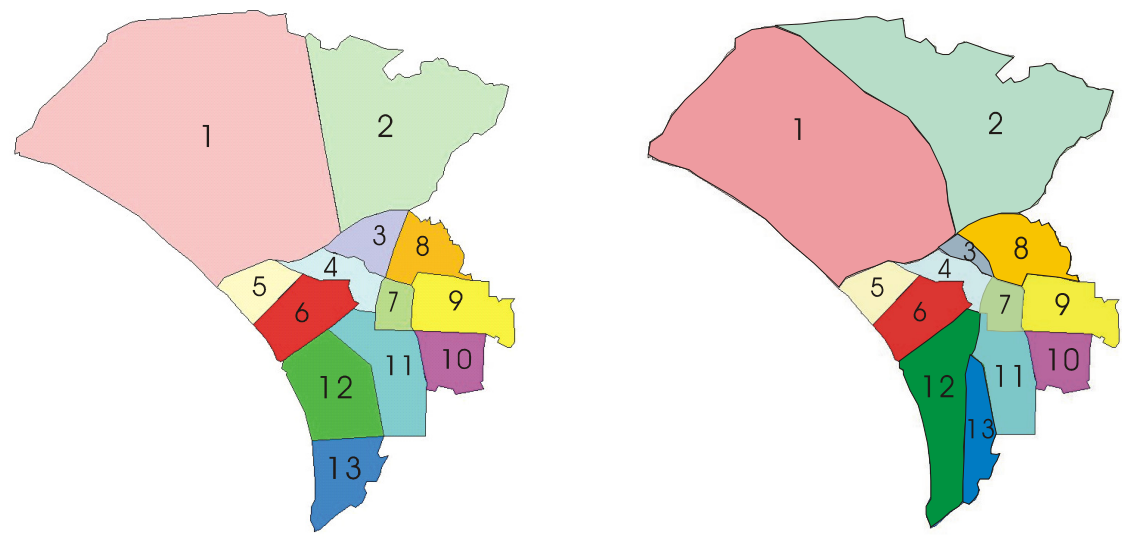

Figure 4: $\quad$ Original and adjusted living areas.

\subsection{Prediction of population migrations}

Regarding the prediction of migration, because the population in Tainan tends toward stable in recent years, the annual growth is not significant, thus, this paper supposes that the present population and industrial distribution, as seen in the sample, would not change in the future.

According to the basic economic theory [4], there are two different industries, which include basic activity and non-basic activity industries. The former means that the industry supplies production outside the area, also called the exogenous sector, while the latter means the industry supplies production inside the area, also called the endogenous sector. Thus, when the land use of the industry is affected, the non-basic industry is difficult to relocate in the service area because it services the demands of the local area; whereas, the basic industry can choose to move out of the original area. Therefore, this paper supposes that, of the flooding area, of the people who belong to the basic industry, half will choose to move out the study area, while the other will move into a non-flooding area; and those belonging to non-basic industry will move within the non-flooding area. 
According to the above content, we quote the "location quotient" as the index to divide the basic and non- basic industries in Tainan city. The results show that the proportion of basic industry is $73.47 \%$, thus, this research supposes that the population moving out rate is $36.73 \%$ in the flooding area; and the proportion of those choosing to move into the non-flooding area is $63.27 \%$, as the statistics for proportions to assign the population.

\subsection{Model of migration assignment}

"The law of universal gravitation" is the most popular method to deal with migrations in space, as applied to social sciences; was and is often utilized to analyse the inter-dynamic relations among areas. This theory is in direct proportion to quality of the object, regarding the size of gravitation, but is in inverse proportion to the square of distance among the objects. When applied to the inter-dynamic relation of space, it shows mutual effort in direct radio with individual size, but inverse proportional to the interval distance. Its mathematics type is shown as formula (1)

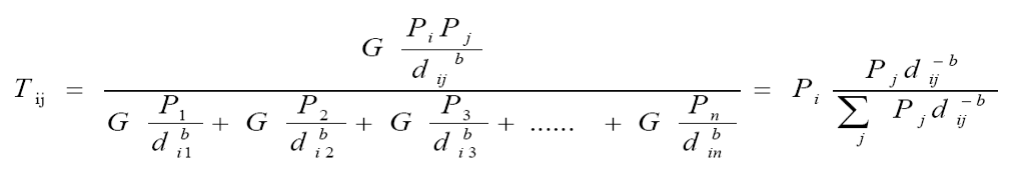

where

$T_{i j}:$ travel frequency from $\mathrm{i}$ to $\mathrm{j} ; P_{i}$ : population in i area

$P_{j}$ : travel opportunity from facilities; $d_{i j}$ : distance from $\mathrm{i}$ area to $\mathrm{j}$ facilities

In addition, the structure of the Hansen method [5, 12] extends to the "gravitation law", and could be use to predict increasing populations assign to each area. Its basic assumption is as follows: First, the distribution of the population increment is influenced by land holding capacity and employment accessibility; minus the population increase rate, which will not appear; and ignores the redistribution from the original population. The model structure is shown as follows:

$$
\begin{gathered}
\Delta P_{i}=\Delta P \times\left(A_{i} V_{i} / \sum_{j} A_{j} V_{j}\right) \\
A_{i}=\sum_{j}\left(E_{j} / d_{i j}\right)
\end{gathered}
$$

where

$\Delta P$ : Total increasing population; $P_{i}$ : Increasing population assigned to i area;

$V_{i}$ : Developing land in i area; $A_{i}$ : Accessibility index in i area;

$E_{i}$ : Employment opportunity in $\mathrm{i}$ area; $d_{i j}$ : Travel time from $\mathrm{i}$ to $\mathrm{j}$ area

In this research, we quote the location quotient of Tainan city, and divide it into basic and non-basic industrial populations. Then, substitute the data into the Hansen Model to assign the migration population in each non-flooding area. The 
Table 1: Calculation results of population, developing land, employment opportunity, and travel time.

\begin{tabular}{|c|c|c|}
\hline Variables & Calculation & Results \\
\hline $\begin{array}{l}\text { Increasing } \\
\text { population } \\
(\Delta P)\end{array}$ & $\begin{array}{c}\text { Total population in flooding areas (Areas } 1 \text {, } \\
3,4,5,6,12 \text {, and } 13 \text { ) cross proportion of } \\
\text { those choosing a non-flooding area } \\
(63.27 \%) .\end{array}$ & $\begin{array}{c}\text { Population: } \\
\text { Flooding area (A): } 231,692 \\
\text { Non-flooding area (B): } 146,581 \\
\text { Outside the study area: } 85,111\end{array}$ \\
\hline $\begin{array}{l}\text { Developing } \\
\text { land }\left(V_{i}\right)\end{array}$ & Calculate the unused land in each area & See Table 2(Developing land) \\
\hline $\begin{array}{l}\text { Employment } \\
\text { opportunity } \\
\left(E_{i}\right)\end{array}$ & $\begin{array}{l}\text { Calculate the land of markets, commercial, } \\
\text { and industry in non-flooding area across the } \\
\text { employment of each unit land (Data from: } \\
\text { Tainan's comprehensive development plan, } \\
\text { Tainan city government ) }\end{array}$ & $\begin{array}{c}\text { Employment of each unit land } \\
\text { (person/square thousand meters) } \\
\text { East area: } 23 ; \\
\text { South area: } 10 ; \\
\text { Middle area: } 30 ; \\
\text { North area: } 43 ; \\
\text { Annan: } 20 ; \text { Anping: } 26\end{array}$ \\
\hline $\begin{array}{l}\text { Travel time } \\
\qquad\left(T_{i j}\right)\end{array}$ & $\begin{array}{l}\text { This paper uses the square straight } \\
\text { distance to represent Travel time (km) }\end{array}$ & See Table 2 \\
\hline
\end{tabular}

Table 2: $\quad$ Empirical data in every non-flooding area.

\begin{tabular}{c|c|c|c|c|c|c|c|c|c}
\hline \multirow{2}{*}{ Area } & \multirow{2}{*}{$\begin{array}{c}\text { Developing } \\
\text { land(meter } \\
\text { square) }\end{array}$} & \multirow{2}{*}{$\begin{array}{c}\text { Employment } \\
\text { opportunity }\end{array}$} & \multicolumn{7}{|c}{ Travel time } \\
\cline { 5 - 10 } & & 2 & 7 & 8 & 9 & 10 & 11 & 13 \\
\hline 2 & $2,741,032$ & 62,227 & 2.8 & 8.544 & 5.696 & 9.072 & 10.992 & 11.232 & 14.032 \\
7 & 33,107 & 39,082 & 8.544 & 0.68 & 2.848 & 3.072 & 3.568 & 2.976 & 6.176 \\
8 & 546,578 & 34,868 & 5.696 & 2.848 & 1.456 & 3.536 & 5.408 & 5.472 & 8.72 \\
9 & 656,250 & 9,227 & 9.072 & 3.072 & 3.536 & 1.68 & 2.496 & 3.92 & 7.264 \\
10 & 288,430 & 5,262 & 10.992 & 3.568 & 5.408 & 2.496 & 1.296 & 2.496 & 5.36 \\
11 & 65,661 & 390 & 11.232 & 2.976 & 5.472 & 3.92 & 2.496 & 1.328 & 3.584 \\
13 & 340,618 & 437 & 14.032 & 6.176 & 8.72 & 7.264 & 5.36 & 3.584 & 0.656 \\
\hline Total & $4,671,676$ & 151,493 & & & & & & & \\
\hline
\end{tabular}

detailed established parameters and data are shown as the following context (Tables 1).

We arrange the above-mentioned data and substitute the developing land, employment opportunities, and travel time in Formula (3) to calculate the accessibility index; then, through Formula (2) to obtain the proportion of migration and assigned population in each non-flooding area (Table 2).

According to the results shown in Table 3, the assigned populations are $71,037,8,053,35,195,20,731,7,291,1,362$, and 2,913, respectively, in each of the non-flooding areas. 
Table 3: $\quad$ Results of assigned population.

\begin{tabular}{ccccc}
\hline Area & Accessibility index & $\mathrm{Al}^{*} V_{i}$ & Assigned proportion & Assigned population \\
\hline 2 & 9,708 & $2.66 \times 10^{10}$ & 0.484 & 71,037 \\
7 & 91,117 & $3.01 \times 10^{9}$ & 0.054 & 8,053 \\
8 & 24,120 & $1.31 \times 10^{10}$ & 0.240 & 35,195 \\
9 & 11,833 & $7.76 \times 10^{9}$ & 0.141 & 20,731 \\
10 & 9,468 & $2.73 \times 10^{9}$ & 0.049 & 7,291 \\
11 & 7,770 & $5.1 \times 10^{8}$ & 0.009 & 1,362 \\
13 & 3,203 & $1.09 \times 10^{9}$ & 0.019 & 2,913 \\
\hline Total & 157,222 & $5.49 \times 10^{10}$ & 1.00 & 146,581 \\
\hline
\end{tabular}

\section{Conclusions and remarks}

\subsection{Impact of rising sea levels on land use}

From the simulation of rising sea levels in Tainan city, we found that for land areas where the rising sea level was not significant, the impact of land use is not serious as expected. However, increasing with height, the impact becomes significant with higher density of land use. Thus, the city planners should star to redeploy the land use for the future Tainan city.

\subsection{Variation of population density under rising sea levels}

Observations of the population assignment, by Hansen model, in Tainan (Table 4). The highest arrangement proportion is in area 2 (Annan district) which has more developed land and industry, and would be an important development area in the future of Tainan. The lowest arrangement proportion is in area 11 (South district of Tainan) which developed slowly at present. From the operations of Hansen model, it shows the entire urban development in future will turn to North and East areas of Tainan city under rising sea levels.

\subsection{Actions at Taiwan under rising sea levels}

There were many typhoons that attacked Taiwan every year. The flooding problem was already getting serious with the unexpected rainfall. For adaption to the change of living areas under rising sea levels, the administrative departments the change of living areas under rising sea levels, the administrative departments in Taiwan besides should pay more attention concerning energy saving and carbon reduction but also readjust the entire land uses for the future Taiwan. 
Table 4: $\quad$ After-assigned population density.

\begin{tabular}{ccccccc}
\hline Area & $\begin{array}{c}\text { Assigned } \\
\text { population }\end{array}$ & $\begin{array}{c}\text { Original } \\
\text { population }\end{array}$ & $\begin{array}{c}\text { After assigned } \\
\text { population }\end{array}$ & $\begin{array}{c}\text { Original } \\
\text { population } \\
\text { density } \\
\text { (person/km } \\
\text { square) }\end{array}$ & $\begin{array}{c}\text { After assigned } \\
\text { density }\end{array}$ & $\begin{array}{c}\text { Increasing of } \\
\text { population } \\
\text { density }\end{array}$ \\
\hline 2 & 71,037 & 122,482 & 193,519 & 2,889 & 4,565 & $58.00 \%$ \\
7 & 8,053 & 44,347 & 52,400 & 14,852 & 17,549 & $18.16 \%$ \\
8 & 35,195 & 104,681 & 139,876 & 13,421 & 17,933 & $33.62 \%$ \\
9 & 20,731 & 106,323 & 127,054 & 14,986 & 17,908 & $19.50 \%$ \\
10 & 7,291 & 87,352 & 94,643 & 15,009 & 16,261 & $8.35 \%$ \\
11 & 1,362 & 28,730 & 30,092 & 3,967 & 4,155 & $4.74 \%$ \\
13 & 2,913 & 34,190 & 37,103 & 3,737 & 4,055 & $8.52 \%$ \\
\hline Total & 146,581 & & & & & \\
\hline
\end{tabular}

\section{References}

[1] Bert Metz, Ogunlade Davidson, Peter Boschf (2007) , Climate Change 2007 - Mitigation of Climate Change, Cambridge University Press.

[2] Cunningham, W. P., Cunningham, M. A. and Saigo, B. W. (2003). Environmental Science: A Global Concern (7th Edition). New York: McGraw-Hill.

[3] Douglas, B.C., (2001): Sea level change in the era of the recording tide gauges. In: Sea Level Rise: History and Consequences. Academic Press, New York, pp. 37-64.

[4] Field, B.G. and Macgregor, B.D., (1987) Forecasting Techniques for Urban and Regional Planning.

[5] Frankena, M.W., (1978) "A Bias in Estimating Urban Population Density Function.” Journal of Urban Economics, Vol.5, pp.35-45.

[6] Lombard, A., et al., (2005): Thermosteric sea level rise for the past 50 years; comparison with tide gauges and inference on water mass contribution. Global Planet. Change, 48, 303-312.

[7] Martin Parry, Osvaldo Canziani, Jean Palutikof (2007) , Climate Change 2007 - Impacts, Adaptation and Vulnerability, Cambridge University Press.

[8] Mitchell, W., J. Chittleborough, B. Ronai, and G.W. Lennon, (2001): Sea level rise in Australia and the Pacific. In: Pacific Islands Conference on Climate Change, Climate Variability and Sea Level Rise, National Tidal Facility Australia, Rarotonga, Cook Islands, 3-7 April 2000. Flinders Press, Adelaide, Australia, pp. 47-57.

[9] Nicholas Stern (2007), The Economics of Climate Change: The Stern Review, Cambridge University Press. 
166 Flood Recovery, Innovation and Response II

[10] Susan Solomon, Dahe Qin, Martin, Manning (2007), Climate Change 2007: Working Group I Contribution to the Fourth Assessment, Cambridge University Press.

[11] Sahagian, D.L., (2000): Global physical effects of anthropogenic hydrological alterations: sea level and water redistribution. Global Planet. Change, 25, 39-48.

[12] Timmermans, H., (2003), "The Saga of Integrated Land Use-Transport Modeling: How Many More Dreams Before We Wake Up", 10th International Conference on Travel Behaviour Research, Lucerne. 